\title{
An Analysis of the Sustainability and the Future of Innovation Readiness within the Australian Supply Base - A Cross-Sectorial, Cross-Regional Snapshot
}

\author{
Dr Lee E J Styger (Author) \\ Director, MBA Program, \\ Sydney Business School, University of Wollongong \\ 175 Liverpool Street, Sydney, New South Wales, 2000, Australia \\ lstyger@uow.edu.au
}

\begin{abstract}
Recently, there has been unprecedented disturbance in the core supply base of many Australian organisations. Supply networks that were once considered robust are in many cases vulnerable. Traditional supply chain development methodologies appear to offer little improvement opportunity due to critical gaps developing at core supply nodes and/or within the critical mass of supply. This paper discusses the data derived from a series of novel cross-sectorial and cross-regional supply chain focus groups and OEM feedback interviews. This paper highlights the potential embedded risks within the supply base of Australia. Importantly this paper demonstrates a disconnect between supplier and customer, a lack of strategic thinking and implementation and chronic systems and technological scarcity within the data set, that will likely be the first threshold barrier for many organisations attempting to engage with their future customers.
\end{abstract}

Keywords-component; strategy, sustainability, supply, innovation, readiness

I.

\section{INTRODUCTION}

There has been much speculation regarding the sustainability and innovation readiness of the Australian supply base in recent times. Alongside standard issues such as globalization and diminishing traditional markets, more recent impacts of the Global Financial Crisis have undermined robust supply networks. In an attempt to provide some basic data concerning the Australian supply base, a research program consisting of the data mining of focus groups backed up by OEM interviews was conducted in 2010 .

The findings of this study generated what is considered to be the first cross-sectorial and cross-regional sample set of the Australian supply base in recent times. As such, this study provides a snap shot of the state and level of readiness and competitiveness within the supply base of Australia.

Whereas there have been countless studies of specific regions and/or sectors previously, little work has been conducted on an entire supply base. The limitations of specific region and/or sector studies is that they could typically focus on the main interaction node within a supply network, but lose site of seemingly unimportant lower level suppliers. An assumption often used in commercial supply chain studies and mapping exercises is that lower level suppliers have little effect in the overall competitive and operational readiness of a supply network. However, if the data from this study is extrapolated, then it becomes apparent that most of the supply base could be significantly below the performance capability necessary to sustain supply networks though out Australia and the combined mass of small suppliers could be the limiting factor on Australia's ability to compete within the global arena.

\section{BACKGROUND TO THE STUdY AND COLLECTION OF THE SAMPLE SET}

The core data for this work was derived from a series of focus groups that were involved in a program of work sponsored by the Australian Federal Government in 2010 to support business development. The focus groups were conducted within major business centres and also regional hubs.

The program was promoted using a series of databases and advertisements in the public electronic and print media. Participants were asked to pre-register for the regional focus group of their choice. As such, the sample set can be determined to be a random (or as near as is possible) representation of Australian business [1]. It should be noted that each business had their own supply base and was involved in at least one traditional customer supply network, and were therefore qualified to take part in the study [2]. Furthermore, all participants were senior officers within their organisations and as such were involved in the strategic aspects of their business, including strategic and operational aspects of their supply chain. 
No qualifying participants were excluded from the study, however, there was, as would be expected, a natural filtering process from the initial contact stage to final participation $[3,4]$. The filtration ratio was 1:64 and is consistent with recognised protocols and it is therefore considered to be a robust sample within the scope of this study [5].

\section{The Rationale, Design AND Piloting of ThE DIAGNOSTICS}

The diagnostics program that formed the body of this research was drawn from proven business modeling, analysis and due diligence methodologies. The diagnostics had been used successfully in many private business improvement consultation programs and supplier selection protocols globally.

In an effort to prove efficacy and relevance to the study from an Australian perspective, the diagnostics were first piloted in several smaller Australian focus groups including; regional industrial groups, chambers of commerce, and professional service focus groups prior to being incorporated into the study [6].

The study was conducted in an environment of an informed and inclusive network. In all cases, participants were provided with support and standard background information [7].

The diagnostics were developed around five key themes, these were:

\section{Analysing Strategic Positioning and Market Trends}

2. Analysing Supply Networks, Supply Competency and Capability

3. Analysing the Potential Risk Inherent within Supply Networks

4. Analysing Technology

5. An Insight into Innovation

It should be noted that the analysis is based on the hypothesis that the focus groups provided an initial random sample of Australian business (i.e. supply base) and the mean averages of the collective focus groups is a representative and robust indicator of Australian supply base. There is no suggestion that there were not some world-class participants within the focus groups, however, it is the sample mean in this case that provides the core indicator of performance not selected "best (or indeed worst) in class" [8].

\section{ANALYSing Strategic Postioning AND MARKeT TRENDS}

The diagnostics for strategic positioning and market trends included:

\section{Determining Competencies and Capabilities}

2. Completing a Five Forces Analysis
3. Identifying the Ideal Market Position

4. Product Platforming

5. Strategic Positioning of Suppliers and Customers

6. Realignment of Current Position to Future Position

7. Developing a Sense of Future Sight in the Sector

\section{Determining Competencies and Capabilities}

Participants were provided with a simple matrix consisting of sections concerning tangible and intangible resources and competencies, intersected by threshold capabilities and capabilities for competitive advantage. After discussion, participants were asked to complete the matrix from the point of view of their own organisations. The findings are shown below:

- $82 \%$ of the participants could not differentiate between a threshold capability (i.e. the fundamental business and sector requirements, necessary to operate successfully within that sector) and capabilities for competitive advantage (i.e. the unique potential within the organisation that could be exploited to differentiate that organisation from its competition)

- $87 \%$ of the participants had difficulty differentiating between resources and competencies within their organisations

\section{Completing a Five Forces Analysis}

Participants were provided with a blank pro-forma of Porters Five Forces Analysis model [9]. After discussion participants were asked to complete the pro-forma from the point of view of their own organisations. The findings are shown below:

- $75 \%$ of participants did not know the basic dynamics in their industry (i.e. they were unable to briefly describe what was currently happening within their own market)

It is important to note that all of the diagnostics were described, discussed and examples given to the participants as a part of the focus groups. As such, it is reasonable to assume that the participants would have been able to provide some level of input.

\section{Identifying the Ideal Market Position}

Participants were asked to identify how they were positioned within the supply network and what additional value their suppliers provided. The findings are shown below:

- $75 \%$ of participants knew how they were positioned within the market

- $15 \%$ of participants could identify the additional value of their suppliers

\section{Product Platforming}

Product platforming is a long established competitive strategy for customer focused organisations and links the concepts of supply with the concepts of innovation [10]. As such, it should be possible to form a tangible measure between the probability of an organisation's sustainability and their 
innovation competency. The findings of this exercise are shown below:

- $\quad 4 \%$ of participants had a product strategy targeted at specific market

- $35 \%$ of participants were satisfied by re-badging or re-pricing old products and services

- $\quad 75 \%$ of participants had no experience in getting a new product to market

\section{Strategic Positioning of Suppliers and Customers}

Participants were provided with two pro-forma's and asked to map where their suppliers and where their customers were strategically positioned. They were also asked to note the key attributes of their suppliers. The finding are shown below:

- $83 \%$ of participants had never strategically positioned themselves, their suppliers or their customers

- $80 \%$ of participants recognised a disconnect between themselves and their customers

\section{Realignment of Current Position to Future Position}

Participants were asked to map how they would move from where they were positioned currently to where they thought they should be in order to provide a sustainable future. The findings are shown below:

- $95 \%$ of participants could not provide a thumbnail picture of where their customers were strategically positioned and in response, where they needed to be to serve those customers

\section{Developing a Sense of Future Sight in the Sector}

This diagnostic consisted of participants being asked to imagine what was likely to be happening within their field of operation in the near future. This exercise had been described as "developing a capacity for over the horizon planning" and participants were asked to establish an "Over The Horizon" (OTH) perspective for their organisations supply. The findings are shown below:

- $25 \%$ of participants had a limited amount of strategic planning beyond the day to day running of the business

- No definitive answer could be provided at any point regarding the question "to what level are strategies communicated."

\section{Analysing Supply Networks, Supply Competency AND CAPABILITY}

The diagnostics for Analysing Supply Networks, Supply Competency and Capability included:

1. Mapping the Supply Chain

2. Re-mapping the Supply Chain

3. Determining Best Customer and Business Blockers

4. Performing a SWOT Analysis of the Supply Network
5. Determining Cost, Value and Performance

6. Transaction and Interaction Capability within the Supply Network

7. Developing LEAN Principles - A Quality Focus

8. The Use of Performance Matrices

9. The Fundamental Starting Point of a Sustainable Supply Network

\section{Mapping the Supply Chain}

This diagnostic was used as the "ice breaker" to the study. Participants were asked to map their organisations supply chain using the "bow tie" model [11]. In many respects, this should have been the simplest exercise for all of the participants. The findings are shown below:

- $80 \%$ of participants could not name their second tier suppliers (this was likened to participants knowing that milk came from the fridge but having no concept that before it got into their fridge, it came from the supermarket)

- $10 \%$ of participants were able to name first, second and more tiers of suppliers

- $15 \%$ of participants could make a tangible connection between supply and the customer

- $90 \%$ of participants could not name a customer internally or externally

- $100 \%$ of all NGO, Government and support providers did not acknowledge that they had a supply chain or indeed supply chain management was relevant for them and/or their stakeholders

\section{Re-mapping the Supply Chain}

Later in the study, and as confidence developed, participants were asked to remap their supply chain with key nodal links (i.e. the main transactional points of their supply network). This diagnostic occurred approximately four hours into the session. The finding of this exercise is shown below:

- $97 \%$ of participants were unable to develop a plausible reference of the interaction points of their internal and/ or external supply

\section{Determining Best Customer and Business Blockers}

Although reverse logistics is a well covered principle in traditional supply theory [12], a little covered aspect of reverse logistics is that of cash flow and the potential scaling and associated risk within a supply network that services poorly paying customers. This exercise developed this aspect of sustainable supply and in particular asked participants to list their customers who had demand for their products and services, but did not pay, and also to list customers who had demand for their products and services and did pay (promptly). The results of this exercise are shown below:

- $100 \%$ of participants could list both the customers who paid promptly and those who did not pay 
- Most participants filled in the column of customers who don't pay rapidly

- $10 \%$ of all customers listed satisfied the "paid" category

\section{Performing a SWOT Analysis of the Supply Network}

Participants were asked to conduct a SWOT (strengths, weaknesses, opportunities and threats) analysis on their supply networks. The results are shown below:

- $95 \%$ participants knew about the SWOT technique

- $30 \%$ were able to perform the analysis on their own supply network with confidence and competence

\section{Determining Cost, Value and Performance}

Participants were asked to complete a simple pro-forma concerning how they thought they were performing within a cost, value and performance constraints. The findings are shown below:

- $90 \%$ of participants were able to manage a price down policy on their suppliers

- $20 \%$ of participants had a program to manage shareholder and/or stakeholder value

- $40 \%$ of participants had used newsletters, public relations and marketing strategies in managing shareholders and/or stakeholders

- $40 \%$ of participants did not manage shareholder value by any means

- $90 \%$ of participants believed that lateness (time-tomarket) was acceptable

\section{Transaction and Interaction Capability within the Supply Network}

Two diagnostics exercises were used to map how the participants believed they were communicating and transacting within their networks and how well their suppliers were communicating and transacting with them. This exercise appeared to be the most challenging for many participants. Many participants wanted to be removed from the process of sales, somehow believing that is was "dirty".

- $84 \%$ of participants were rated as being poor at corporate communications between themselves, customer and suppliers

- $13 \%$ of participants were good at communications and selling

- $16 \%$ of participants believed that their suppliers were good at communicating and selling to them

\section{Developing LEAN Principles - A Quality Focus}

LEAN principles were discussed within the study as were formal quality management systems. The findings are shown below:

- $90 \%$ of participants thought the concept of LEAN would be useful in their organisations
- $10 \%$ of participants thought they could actually introduce LEAN principles into their organization, the main barrier to introduction being internal cultural axioms

- $12 \%$ of participants were using some aspects of LEAN

- $11 \%$ of participants recognised that they were operating within a formal quality management system

- $6 \%$ of participants were operating within a formal, externally audited, quality management system

\section{The Use of Performance Matrices}

Two further matrices were offered to the participants in order to establish how they were currently performing within their supply network and what they needed to do to improve and sustain performance. Fundamentally, these two matrices were an extension of developing LEAN principles and a quality focus. The findings are shown below:

- $12 \%$ of participants attempted both performance matrices exercises

- $50 \%$ were able to collate an answer regarding basic supply chain management performance measures

- Of the $50 \%$ who attempted the exercise, the average performance rating was $40 \%$

9. The Fundamental Starting Point of a Sustainable Supply Network

This exercise was designed to get participants started in terms of developing sustainable supply networks. It consisted of six basic questions and an opportunity to develop a simple position statement or statement of intent for improvement. The findings are shown below:

- $3 \%$ of the participants were able to perform this exercise in detail

\section{ANALYSING THE POTENTIAL RISK INHERENT WITHIN SUPPLY NETWORKS}

The diagnostics for analysing the potential risk inherent within supply networks included:

\section{Analysing a Potential Immediate Stop in Supply}

2.Analysing a Potential Stop in Future Supply

3.Risk Analysis Planning

\section{Analysing Technological Risk}

\section{Analysing a Potential Immediate Stop in Supply}

This diagnostic asked for participants to predict what could happen immediately to their business that would stop them getting the resources they needed to operate. The findings are shown below:

- $70 \%$ of participants were unable to predict what could happen to their organisation if there was an immediate stop in supply to their organization 


\section{Analysing a Potential Stop in Future Supply}

In this diagnostic, participants were asked to draw out what would happen today to stop their organisations getting the resources that they needed to operate into the future. The findings are shown below:

- $85 \%$ of participants were not able to identify what could happen to their organisations if there was a break in supply at some point in the future

- $15 \%$ of participants were able to accurately communicate the ramifications for their organisation if there was a break in supply at some point in the future

\section{Risk Analysis Planning}

In this diagnostic, participants were asked to develop a simple analysis profile consisting of the top five risks in their current supply chain. The findings are shown below:

- All participants were senior officers within their organisations and knew of the concept, but

- $\quad 95 \%$ of participants had never completed a formal risk analysis on their supply chain

\section{Analysing Technological Risk}

In completing the supply chain "Sanity Check List" and the "Technology Audit" it was apparent that these concepts were foreign to most participants. The completion of these diagnostics were typically discounted by most of the participants. This may be due to an inadequacy in understanding basic supply chain concepts or diagnostic fatigue, however further investigation highlighted the disturbing trend that, whereas most senior officers were well aware that technology should be appropriate, efficient and accessible within their organisations, most typically outsourced the decision, control and performance measures. The findings are shown below:

- $5 \%$ of participants were able to achieve an adequate benchmark on the overall performance and sustainability of their supply chain

- $23 \%$ of participants considered their systems and technology to be performing within acceptable industry standard expectations

\section{A SNAPSHOT OF INNOVATION PERFORMANCE WiTHIN THE AUSTRALIAN SUPPLY BASE}

Seven key questions were posed to the focus group participants concerning the innovation performance within their organisations. The questions were:

1. A Rating of Organisational Innovation

2. A Rating of Customer Innovation

3. A Rating of Competitors Innovation

4. Capability in Getting New Products to Market

5. Skills to Implement Innovation Strategy

6. Customer Focused Innovation

\section{Differentiated Innovation within the Business Process}

\section{A Rating of Organisational Innovation}

Participants were provided with a pro-forma and asked to rate the innovation in their organisation. The findings are shown below:

- The basic question delivered a performance level of $68 \%$ within the total focus groups

- $11 \%$ of participants thought that they were excellent (world class)

\section{A Rating of Customer Innovation}

Participants were provided with a pro-forma and asked to rate the innovation in their customers. The findings are shown below:

- The basic question delivered a performance level of $62 \%$ within the total focus groups

- $6.4 \%$ of participants thought that their customers were excellent (world class)

- $40 \%$ of participants thought that their customers were good or above

\section{A Rating of Competitor Innovation}

Participants were provided with a pro-forma and asked to rate the innovation in their competitors. The findings are shown below:

- The basic question delivered a performance level of $62 \%$ within the total focus groups

- $5.5 \%$ of participants thought that their competitors were excellent (world class)

- $41 \%$ of participants thought that their competitors were good or above

It should be noted that participants were being asked to rate innovation within their own current organisation, their suppliers and their customers. As such, a perception of World Class, for example, represents a measure in total but from the participants local perception. At first sight, this would appear to be acceptable, however, participants own and their customers real competitiveness is based on their ability to innovate and therefore be sustainable in the free market.

An intriguing insight began to develop when participants were asked about their competitors. Overall, the spread of data showed an overall improvement shift of approximately $40 \%$ (i.e. because they were measuring their competitors they would naturally mark down). Typically, it would be logical to expect to see a lower true measure of competitor performance against personal performance, because of natural negative scaling. However, the distribution of measure was higher overall (40\%) indicating that, even after negative scaling, participants rated the innovation in their competitors significantly higher than their own. 


\section{Capability in Getting New Products to Market}

Participants were provided with a pro-forma and asked to rate their organisations ability to get new products to market successfully. The findings are shown below:

- The basic question delivered a 59.2\% overall average

- $8.2 \%$ of participants thought that they were excellent (world class)

- $34.8 \%$ of participants thought they were good or above

It should be noted that the focus group diagnostics established that $75 \%$ of the participants did not know how to get a product to market and yet when posed with the same question in an innovation context, participants felt obliged to answer positively.

\section{Skills to Implement Innovation Strategy}

Participants were provided with a pro-forma and asked to rate the level of skill within their organisation to implement their innovation strategy (on the assumption they had an innovation strategy). The findings are shown below:

- The basic question delivered a $67.5 \%$ overall average

- $9.1 \%$ of participants thought that they were excellent (world class)

- $55 \%$ of participants thought that they were good or above

The responses were somewhat in conflict with earlier responses from the focus groups regarding sector dynamics and customer positioning, specifically:

- $75 \%$ of the participants had already stated that they did not know the basic dynamics of their sector

- $95 \%$ of the participants could not strategically place their customers suggesting that any innovation strategy would have limited effect

\section{Customer Focused Innovation}

Participants were provided with a pro-forma and asked to rate the level of customer focused innovation within their organisation. The findings are shown below:

- The basic question delivered a $74.6 \%$ overall average

- $32.1 \%$ of participants thought that they were excellent (world class)

- $64.2 \%$ of participants thought that they were good or above

Once again these responses were in conflict with earlier responses from the focus groups regarding customer positioning and communication, specifically:

- $95 \%$ of the participants could not strategically place their customers
- $80 \%$ of the participants recognise a disconnect between themselves and their customers

- Responses from the focus groups indicated that participants were generally poor at identifying and communicating with customers and suppliers

\section{Differentiated Innovation within the Business Process}

A simple exercise was presented and discussed with the participants of the focus groups concerning how they could differentiate their organisation by adopting business processes based around two out of three performance indicators; Good Fast - Cheap.

Participants were asked to circle any of the performance indicators that best described their organisations differentiation position (i.e. did they consider themselves to be good and fast for example). There appeared to be an overwhelming desire by all participants to circle all of the three performance indicators and as such place themselves in a fully constrained and hyper competitive environment.

$80.7 \%$ of participants had an element of "Good" within their answer, forcing the question "By what measure?" Unfortunately this could not be answered simply by any of the participants.

\section{A GENERAL ANALYSIS OF THE RESPONSES FROM THE FOCUS GROUP PARTICIPANTS}

A list of key perceptions were developed by the focus group facilitators during the course of the study. Whereas the perceptions cannot be considered to provide a quantitative measure of the sample, they were repeatedly and independently recorded (by multiple facilitators) and as such should be considered as relevant supporting qualitative data [13]:

A majority of the participants had very little knowledge of the concept of supply and were unable to trace their supply past Tier 1 . For example, they understood where their new season dress came from (Supplier 1) but had not thought about where the dress was made, how the fabric was made, where the buttons came from

- A majority of the participants had no appreciation of the risk of supply and what would happen if a small supplier some tiers down fails and is unable to supply a component

- A majority of the participants placed a high importance on the running of their business, and did not have mechanisms to ensure they were taking the same care of their customers and indeed their suppliers

- There is a perception that Supply Chain and Logistics is the responsibility of one or two middle management and shop floor employees 
and not something everyone in the organisation should be aware of

- There is a disconnect between what happens in one part of the supply chain and the next person down the line (i.e. the customer)

- $\quad$ Supply chain is logistics (i.e. trucks and stock movement), not people, places and education

- Supply Chain is volume and you have to be concerned with the channeling of volume for a supply chain to exist

- There is very little in the way of formal measures and control in Australian business or supply chains

- Businesses are struggling to manage supply chains that are changing constantly due to the disappearance of key suppliers

- Government representatives (i.e. any person working for government, council or a not-forprofit that attended a workshop) did not recognise they had customers or a supply chain. The most alarming was that most industry groups that were approached as a part of this program did not think supply chain was important to their organisation or their members

\section{STATE OF THE SUPPLY BASE - THE EFFECT OF DIP DYNAMICS AT THE POINT OF THE STUDY}

The study was conducted in the latter part of 2010. At the time, it was thought that industry was beginning to recover from the effects of the Global Financial Crisis of 2008 - 2009.

The Dip Dynamics model describes the fall of operations during the economic crisis of 2008 - 2009 and then the risks of re-growth [14]. The principle of Dip Dynamics is straightforward and assumes that companies have been operating at a nominal $100 \%$ for their system pre the economic crisis (i.e. they were operating at the maximum they could achieve based on their capability in a strong economic environment). Rapidly, their marketplace retracted. In many cases by over $50 \%(60 \%-80 \%$ have been reported), causing the business leaders to cut their operations by at least half.

The downsizing included internal and external elements. However, the dynamic is not that simple, because, initially, if a company had to cut its business by half, then they were forced to cut their resources, inventory, people and supply chain by more than half because of the long tail of supply.

Typically the supply chain has downsized rapidly and this has had the effect of reducing dramatically the available capability. This is not to say that there is no supply capability, but rather it is fragmented and dispersed causing scarcity in what is becoming time of need. Put simply there is a growing requirement and a shrinking availability in the market causing a duel widening of the supply gap.

\section{A Regional Case Study of Terminal Economic DECLINE DUE TO FUTURE SUPPLY GAPS}

During the course of the study, it came to light that many regions throughout Australia were suffering because basic local suppliers were diminishing. Whereas a body of data is difficult to draw on currently, one anonymous source from a regional government organisation provided the following data regarding their region:

- The region sustains 20,000 small businesses

- Each business employs less than 5 people each

- 18,000 of these businesses have no succession plan

- In approximately 5 years most of the managers will have "moved on" due to retirement or pursuing other interests

The impact on the economy will be terminal because:

- Post the Global Financial Crisis, there is no-one wanting to take a high risk investment decision for a low return option (i.e. a gap in supply of investment)

- Because of diminishing activity and businesses, there will be no-one capable to step into the roles (no-one has been trained or qualified)

- There will be no basic supply base within the region

- Customers (businesses, families and governments etc.) will look further afield for critical suppliers and as a result will adopt other suppliers closer to the new critical ones and thus diminish the original supply base further, that in turn speeds up the decline

- Critical supply and therefore economic mass will not be met

It must be accepted that there is a duality of risk within the Australian supply base and whereas organisations naturally focus much effort on Tier 1 suppliers and devolve responsibility (roll shift) down the supply chain. Further, clear and present danger lies within a local supply base that directly and indirectly supports the whole infrastructure of the OEM and importantly its supply network.

\section{XI.}

\section{TRENDS IN SUPPLY ENGAGEMENT}

Post the focus group element of the work, a series of interviews were conducted with senior managers in traditional OEM's with a view of understanding the implications of the focus group findings on the OEM businesses.

Most of the interviewees indicated that their organisations had been experiencing an increase in "negative contribution" within "invisible sections or lower level, smaller and typically insignificant, suppliers". 
A consistent pattern of future supplier engagement was also forthcoming during the interviews. The pattern consisted of four key points, these were:

1. Move to larger lower risk suppliers - the interviewees stated that they were now seeking larger organisations to supply to them because they were perceived to present less risk within the supply network.

2. Need for transparency - transparency and traceability within the supply network was considered to be a significant issue for companies seeking sustainable supply.

3. Need for systems - because of the need for transparency, traceability and also consistency, interviewees stated that they now required formal business and quality management systems to be embedded within their supply networks.

4. Need for continuation of supply - one of the key drivers was continuity of supply, typically summarised as "right - on time - every time".

\section{ThE PARADOX OF LOICAL SUPPLY SURVIVAL}

For years prior to the Global Financial Crisis, there was a call from every business advisor, management consultant and supply chain professional stating that many Australian suppliers needed to invest in business systems, technology and people if they were to be competitive and sustainable within Australian and indeed global supply networks. There does however appear to be a disturbing paradox insofar as those who survived the economic crisis were those who typically did not invest in:

- Technology and Infrastructure

- Business Systems (i.e. formal quality management systems)

- People

Unfortunately, feedback from larger customers (typically OEM or Tier 1) is that it is these very reasons why once qualified suppliers, will now be precluded from future supply networks.

\section{A WidENING GAP IN AUSTRALIAN SUPPLy AND DEMAND}

Under the guise of better corporate social responsibility and transparency, many larger customers are now stipulating core threshold capabilities for their suppliers. In the context of this work, the main barriers are:

- Size of organisation - specialist knowledge capital does not always reside in larger suppliers in the Australian context but rather smaller, often boutique, providers who are automatically precluded from supplier selection matrices based on size of the organization

- Contract value as a percentage of total work in progress - there is simply not enough work flow in many organisations to prove, via standard financial practices, that they are viable within the supply base

- Almost instant response - that assumes excess capacity is available on demand from every supplier and almost always the specialist supplier

Put simply, Australia does not have the critical mass of demand to develop core suppliers on the scale of other competing nations and yet customers expect the same rules of engagement to apply.

There is little doubt that the Global Financial Crisis decimated many strong and mature supply networks and as such many supply networks currently contain significant, and in many cases invisible, risk. Continuity of supply cannot typically be guaranteed and outages either from a physical stock of product point of view or from a human or infrastructure point of view are now common in many networks.

Changes in regulatory policy and compliance are also introducing new business continuity risks due to the enforced "outages" of once skilled practitioners (i.e. the oil and gas sector for example) [15].

Whereas these occurrences might be considered as either containable or manageable within the current economic and market climate, they will almost certainly undermine the foundation of any supply network into the future and render that supply network unsustainable.

\section{XIV.}

\section{CONCLUSIONS}

This work has delivered a unique cross-sectorial and crossregional study, delivering a snap shot of the health and sustainability of supply within Australian business.

In many cases those organisations who have been able to weather the storm of the Global Financial Crisis and are less able to supply now, and in many cases are poorly positioned to supply into the future.

There is a significant disconnect between the supplier and customer and little evidence of measurable channel development or product/service innovation being conducted to effect real change. Likewise, there is a significant gap in threshold knowledge and skills concerning innovation and sustainability throughout supply networks.

Threshold and competitive capabilities are not well understood in most organisations and technology is not well exploited. Paradoxically, despite the long held axiom, of itself, technology will not provide a competitive advantage, however, it is the lack of technology and formal business systems that will be the first barrier of entry into supply networks post the Global Financial Crisis.

In an environment of increasing supply gaps and supply risks, and coupled with an environment of increased corporate 
social responsibility, it is likely that old school supply chain management practices will be the trigger point of downfall of many, once great, organisations. It is also likely that these trigger points will remain highly visible within the supply networks, but remain unchallenged and therefore not acted upon, because most organisations will remain focused on the fiscal bottom line that is manifest by a "re-gifted" product delivered though a supply channel held together with sticking plaster.

Typically, it would appear that responsibility of much of any supply network has been outsourced and is effectively controlled by lower tiers of supply. These tiers are typically small, anonymous and almost ghostlike entities, it is unlikely that there will be much warning of a catastrophic collapse in supply. Rather it is likely to happen one drip at a time into the corporate bucket until it overflows one day, or "one more straw on the back of the camel of supply" until that camel simply collapses and can go no further.

\section{RECOMMENDATIONS FOR FURTHER WORK}

The recommendations for further work include the expansion of the methodology of this study to include a larger sample set of focus group participants to establish if the data is robust. It is also recommended that the same focus group methodology is conducted within alternative international supply bases to establish if there is a correlation between the Australian study and other international supply networks.
[1] S. Gibilisco: Statistics Demystified, McGrawHill, 2004. ISBN 0-07-143118-7

[2] K. Boyer and R. Verma: Operations and Supply Chain Management for the 21st Century, South-Western Cengage Learning, 2010. ISBN-13: 978 0-618-74933-1

[3] P. Bains, C. Fill and K. Page: Marketing, Oxford University Press, 2008. ISBN 978-0-19-929043-7

[4] G. Belch and M. Belch: Advertising and Promotion, An Integrated Marketing Communications Perspective, McGraw-Hill Irwin, 2007. ISBN-13 978-0-07-310126-2

[5] C. Craig and S. Douglas: International Marketing Research, John Wiley \& Sons Ltd, 2005. ISBN 0-470-0109509

[6] J. Gill and P. Johnson: Research Methods for Managers, Sage, 2010. ISBN 978-1-84787-093-3

[7] A. Bryman and E. Bell E: Business Research Methods, Oxford University Press, 2007. ISBN 978-0-19-928498-6

[8] D. Montgomery and G. Runger: Applied Statistics and Probability for Engineers, John Wiley \& Sons Inc, 1999. ISBN 0-471-17027-5

[9] M Porter: Competitive Strategy: Techniques for Analyzing Industries and Competitors, The Free Press, 1998.

[10] L. Sage: Winning the Innovation Race, John Wiley and Sons Inc., 2000. ISBN 0-471-33346-8

[11] S. Fawcett, L. Ellram and J. Ogden: Supply Chain Management, From Vision to Implementation, Pearson Prentice Hall, 2007. ISBN 0-13-101504-4

[12] K. Lysons and B. Farrington: Purchasing and Supply Chain Management, Prentice Hall, 2006. ISBN-13: 978-0-273-69438-0

[13] M. Easterby-Smith, R. Thorpe and P. Jackson: Management Research, Sage Publishing Inc., 2008. ISBN 978-1-84787-176-3

[14] L. Styger: Perspectives on Supply Post the Global Financial Crisis, Wiggly Tin Company, 2009. ISBN 1449967973

[15] J. Fletcher: Good Corporate Governance and Sustainability - A Loss of Containment Issues and Asset Management Challenge, Sydney Fellows Forum, SB360, Wiggly Tin Company, 2009. ISBN 1449530001

\section{REFERENCES}

